\title{
"The effect of ambiguity on the UK stock market: evidence from a new empirical approach"
}

\begin{tabular}{|c|c|}
\hline AUTHORS & $\begin{array}{l}\text { Run Qing Tan } \\
\text { Viktor Manahov } \\
\text { Jacco Thijssen }\end{array}$ \\
\hline ARTICLE INFO & $\begin{array}{l}\text { Run Qing Tan, Viktor Manahov and Jacco Thijssen (2017). The effect of } \\
\text { ambiguity on the UK stock market: evidence from a new empirical approach. } \\
\text { Investment Management and Financial Innovations, 14(4), 133-147. } \\
\text { doi:10.21511/imfi.14(4).2017.12 }\end{array}$ \\
\hline DOI & http://dx.doi.org/10.21511/imfi.14(4).2017.12 \\
\hline RELEASED ON & Friday, 22 December 2017 \\
\hline RECEIVED ON & Wednesday, 18 October 2017 \\
\hline ACCEPTED ON & Friday, 15 December 2017 \\
\hline LICENSE & $\begin{array}{l}(c) \text { EY-Ne } \\
\text { This work is licensed under a Creative Commons Attribution-NonCommercial } 4.0 \\
\text { International License }\end{array}$ \\
\hline JOURNAL & "Investment Management and Financial Innovations" \\
\hline ISSN PRINT & $1810-4967$ \\
\hline ISSN ONLINE & $1812-9358$ \\
\hline PUBLISHER & LLC "Consulting Publishing Company "Business Perspectives" \\
\hline FOUNDER & LLC "Consulting Publishing Company "Business Perspectives" \\
\hline
\end{tabular}

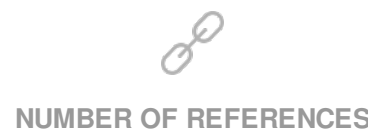

36

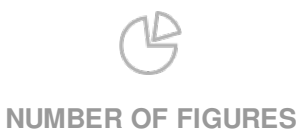

5

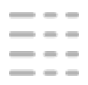

NUMBER OF TABLES

8

(C) The author(s) 2022. This publication is an open access article. 


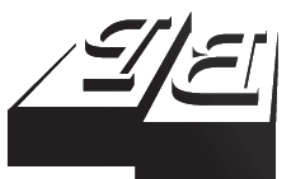

BUSINESS PERSPECTIVES

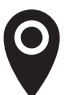

LLC "CPC "Business Perspectives" Hryhorii Skovoroda lane, 10, Sumy, 40022, Ukraine

www.businessperspectives.org

Received on: $18^{\text {th }}$ of October, 2017 Accepted on: $15^{\text {th }}$ of December, 2017

(c) Run Qing Tan, Viktor Manahov, Jacco Thijssen, 2017

Run Qing Tan, Ph.D. Student, The University of York Management School, UK.

Viktor Manahov, Dr., The University of York Management School, UK.

Jacco Thijssen, Professor, The University of York Management School, UK.

\section{THE EFFECT OF AMBIGUITY ON THE UK STOCK MARKET: EVIDENCE FROM A NEW EMPIRICAL APPROACH}

\begin{abstract}
This study developed a new ambiguity measure using the bid-ask spread. The results suggest that the degree of ambiguity has an impact on the daily UK stock market returns, but ambiguity does not cause changes in the returns. This implies that UK stock prices or returns cannot be predicted using variation in the degree of ambiguity through linear models, such as the VAR model, which was used in the study. The two sets of results in the study show that the degree of ambiguity from the previous two days might affect stock market returns. The authors observe that an increase in the degree of ambiguity two days ago is associated with a positive premium required by the investors. On the other hand, the degree of ambiguity tends to be affected by its past five-day values. Thus, the degree of ambiguity seems to persist for five days until investors update their priors. The intuition behind the result is that the degree of ambiguity can affect the returns of the UK stock market and UK stock market returns can in turn have an impact on the degree of ambiguity. The authors also observe that the degree of ambiguity does not seem to predict stock market returns in the UK when one applies linear models. However, this does not mean that there is no non-linear relationship between the degree of ambiguity and stock market returns or stock returns.
\end{abstract}

\section{Keywords}

JEL Classification ambiguity measure, ambiguity aversion, uncertain probabilities

D81, D83, G11, G12

\section{INTRODUCTION}

Ambiguity, which is also known as Knightian uncertainty (Knight, 1921), refers to the uncertainty in probability distribution of asset prices due to misinterpretation or lack of information. Since Ellsberg's experiment showed the invalidity of the independence axiom of the subjective expected utility (SEU) theory (Ellsberg, 1961), ambiguity has been a popular topic. Dow and Werlang (1992) and Garlappi et al. (2007) studied the effect of ambiguity on portfolio choice based on the multiple-prior model.

The authors demonstrated that the multiple-prior model performs empirically better than the classic mean and variance approach and the Bayesian approach when the investors are ambiguity-averse. Routledge and Zin (2009) investigated the impact of ambiguity on liquidity and found that investors behave under multiple-prior preferences. Ozsoylev and Werner (2011) also studied the effect of ambiguity on liquidity and they proved that ambiguity can be associated with illiquid financial markets, since market makers chose not to participate in the market when there is lack of information. Ambiguity is also believed to have contributed to the 2008 financial crisis. The empirical study of Boyarchenko (2012) showed that an increase in ambiguity
This is an Open Access article, distributed under the terms of the Creative Commons Attribution-NonCommercial 4.0 International license, which permits re-use, distribution, and reproduction, provided the materials aren't used for commercial purposes and the original work is properly cited. 
could statistically explain the increase in the credit default swap (CDS) spreads, which led to the 2008 financial crisis. Therefore, both the theoretical and empirical studies seem to suggest that ambiguity is closely related to liquidity of the financial markets.

The concept of the degree of ambiguity and ambiguity aversion is abstract, which can be measured using simulation, but hard to measure by applying real-life data. This inspires us to develop an empirical method using the bid-ask spread to measure the degree of ambiguity with reference to the economic theories in ambiguity.

Another motivation for us to conduct this study is that although ambiguity asset pricing theories are well-established and there are a relatively large number of existing theoretical literature on ambiguity asset pricing, the number of empirical studies remain few. This can be contributed to the difficulties in measuring the degree of ambiguity or ambiguity aversion empirically. Ambiguity utility models include the smooth model, which was developed by Klibanoff et al. (2003), and the multiplier model, which was originally developed by engineers to do robust control (Hansen \& Sargent, 2001; Anderson et al., 2003). The ambiguity utility models can be discrete or dynamic. However, dynamic models are even harder to be applied to real life. The multiple-prior model and the multiplier model are widely used because they are less controversial (Epstein \& Schneider, 2010).

Existing empirical studies are mostly based on the multiple-prior model, but since it does not require the calculation of entropy, which is hard to estimate empirically while necessary to estimate if the multiplier utility model is adopted. Therefore, our empirical study is based on the discrete-time multiple-prior utility model, which makes our empirical work easy to conduct and in the meantime does not require simulations and pre-set values. Viale et al. (2014) used the idea of the multiple-priors utility to construct a learning model under the presence of ambiguity and then investigated the effect of ambiguity on the pricing process of the US cross-section stocks. However, they introduced entropy to measure the distance between the reference prior and the worst-case prior and hence they had to pre-set the confidence level of decision-makers to calculate the entropy. Nevertheless, their results imply that ambiguity is priced and the pricing effect cannot be substituted by other risk or uncertainty factors. Other empirical studies mainly focus on portfolio choice problems. For instance, Dimmock et al. (2016) investigated market participation of households under ambiguity. They found that investors under-diversified their portfolios due to ambiguous information and the 2008 financial crisis could be contributed to ambiguity aversion.

In contrast to the above studies, we developed a new empirical approach to measure the degree of ambiguity using the bid-ask spread. This idea is inspired from the theoretical literature (e.g., Routledge \& Zin, 2009; Ozsoylev \& Werner, 2011), which showed the effect of ambiguity on liquidity.

On the other hand, we follow Epstein and Schneider (2010) to establish the relationship between degree of ambiguity and equity premium and to develop an empirical measure of the degree of ambiguity using the bid-ask spread. We eliminated the impact of market makers on the spread according to microstructure theories of financial markets. We implemented the Grossman and Miller (1988) market making model to construct a spread measure of ambiguity that is orthogonalized to the impact of market makers and liquidity traders. Since there was little existing empirical literature on the relationship between ambiguity and stock returns, especially in the UK stock market, we used a VAR model, which enabled us to analyze the interactions between the degree of ambiguity and the UK stock market returns in a system.

We have found that an increase in the degree of ambiguity in the previous two days is associated with an increase in the daily UK stock market returns. Moreover, the degree of ambiguity seems to persist for five days until investors update their prior. 
However, the results of the Granger causality test suggest that the degree of ambiguity may not be used as a signal to predict any patterns of the stock market returns in the UK. Since the VAR model is based on linearity, we can conclude is that an increase in ambiguity cannot predict price increase linearly. Hence, predictability could exist when non-linear models are applied. For instance, results of Viale et al. (2014) implied that variation of the degree of ambiguity could predict stock prices using the logistic smooth transition autoregressive (LSTAR) model, which is a non-linear model.

The main contributions of this paperto the ambiguity studies are three-fold. First, we provided a new empirical approach to measure ambiguity and this measure does not require pre-set values, meaning that all the data applied are real-life. Second, we investigated the effect of ambiguity on the UK stock market, which has not been well-studied. Third, we showed empirically that ambiguity has an impact on the UK stock market returns, but it does not cause the returns, which means that ambiguity might not be used to predict the UK stock market returns using linear models. On the other hand, we also provided motivations for future studies to use non-linear models to study the effect of ambiguity or ambiguity-aversion on asset pricing.

The remaining sections are organized as follows. In section 1, we briefly introduce the theories related to the multiple-priors model that we used in our study. In section 2, we provide a description of the data.

Section 3 describes the methods that we used to implement our research, followed by section 4 , where the empirical results are presented. In addition to the discussion of the empirical results, we also include a discussion of the results from the robustness analysis in section 5. Finally, we did a short summary and conclusion in final section.

\section{A MULTIPLE-PRIORS SETTING OF ASSET PRICING}

\subsection{The Ellsberg's experiment}

The ambiguity literature is inspired from the Ellsberg's experiment (Ellsberg, 1961) and hence we begin the illustration of the multiplepriors utility model with the Ellsberg's experiment. The basic idea is that there are two urns with uncertainty, one of which is known as an ambiguous urn and the other, a risky urn. In the ambiguous urn, which we denote as Urn 1, there are 100 red balls and black balls, which is the only piece of information that is known to a decision-maker. The risky urn, which we denote as Urn 2, is composed of 50 red balls and 50 black balls and thus, the decision-maker has more information about the composition of the urn now. Then the decision-maker is asked to bet on the color that is drawn from either Urn 1 or Urn 2. Therefore, he has four options, which are betting red from Urn 1, betting black from Urn 1, betting red from Urn 2 and betting black from Urn 2. Table 1 summarizes the options that the decision-maker can choose.

Table 1. Contingency table of Ellsberg's experiment

\begin{tabular}{c|c|c}
\hline & Red & Black \\
\hline Urn 1 & Red from Urn 1 & Black from Urn 1 \\
\hdashline Urn 2 & Red from Urn 2 & Black from Urn 2 \\
\hline
\end{tabular}

On the other hand, Table 1 also tells us that there are four possible outcomes, which are drawing a red ball from Urn 1, drawing a black ball from Urn 1, drawing a red ball from Urn 2 and drawing a black ball from Urn 2. We can assign payoffs to these outcomes to construct a table that summarises the decisions, outcomes and corresponding payoffs. The payoffs are assigned in a way that if the decision-maker has a right guess, he will be awarded 100 and he will get nothing if his guess is wrong. Table 2 illustrates the decisions, outcomes and payoffs regarding Urn 1 and Urn 2, respectively.

Now suppose that the decision-maker can randomise his choice and hence he can toss a fair coin (50-50 percent chance for head and tail to show up) to decide which color to bet from Urn 1 . 
Table 2. Decisions, outcomes and payoffs of ambiguous urn (Urn 1) and risky urn (Urn 2)

\begin{tabular}{|c|c|c|}
\hline Urn 1 & Red & Black \\
\hline Bet red & 100 & 0 \\
\hline Bet black & 0 & 100 \\
\hline Urn 2 & Red & Black \\
\hline Bet red & 100 & 0 \\
\hline Bet black & 0 & 100 \\
\hline
\end{tabular}

Notes: "Red" and "black" in the first row represent the outcomes of a red ball and a black ball, respectively; "bet red" and "bet black" in the first column represent the decision-maker's decisions (also known as acts in economic terms) of betting a red ball and betting a black ball, respectively.

Now the ambiguous urn resembles the risky urn in the sense that the randomisation process is equivalent to assigning a probability of 0.5 for the red ball to turn up and a probability of 0.5 for the black ball to turn up. However, under the subjective expected utility (SEU) theory, a decision-maker should be indifferent among two indifferent options and a randomized combination of them, which is what the independence axiom tells. In mathematical terms, if for any two options $f, f^{\prime}$ and $f: f^{\prime}$ then

$\alpha \cdot f+(1-\alpha) \cdot f^{\prime} \sim \alpha \cdot f^{\prime}+$

$+(1-\alpha) \cdot f^{\prime} \sim \alpha \cdot f+(1-\alpha) \cdot f$,

where $\alpha \in[0,1]$ and " $\sim$ " denotes that two options are indifferent.

We can rewrite equation 1 as

$$
\alpha \cdot f+(1-\alpha) \cdot f^{\prime} \sim f^{\prime} \sim f .
$$

However, from the Ellsberg's experiment, we know that

$\alpha \cdot f+(1-\alpha) \cdot f^{\prime}>f^{\prime} \sim f$

where $\alpha=0.5$ in our illustration.

Therefore, the result from the Ellsberg's experiment violates the independence axiom of the SEU model, which inspires the development of ambiguity studies.

\subsection{Multiple-prior utility model}

Gilboa and Schmeidler (1989) developed the multiple-prior model with a utility function:

$$
U(f)=\min _{p \in C} \int u(f) d p,
$$

where $C$ is a set of priors, $f$ stands for an act, $u$ represents a von Neumann-Morgenstern (vMN) utility function (von Neumann \& Morgenstern, 1944), which is also known as subjective expected utility (SEU) function, and $p$ is the prior probability.

The rationale behind the model is that a decision maker assigns a range of probabilities to a possible outcome and adopts the minimal probability or the worst-case scenario, which reflects that he/she is ambiguous-averse. Then the preference on a decision is ranked with respect to the utility of the worst-case scenario and the decision maker maximizes his/her utility and allocates his/her wealth according to the ranking. Thus, the decision process is made up of a minimization and a maximization procedure, and hence this model is also known as MaxMin expected utility.

The multiple-prior model is widely applied. Dow and Werlang (1992) and Garlappi et al. (2007) studied the effect of ambiguity on portfolio choice based on the multiple-priors model. Routledge and Zin (2009) and Ozsoylev and Werner (2011) investigated the impact of ambiguity on liquidity and found that investors behave under multiple-prior utility. Viale et al. (2014) did an empirical study on the learning process in asset pricing using the multiple-prior model and showed that ambiguity measure was statistically significant in the learning process of asset pricing. The multiple-prior model is frequently used partly, because evidence has been found that it performs better than the classic mean and variance approach and the Bayesian approach empirically when the inves- 
tors are ambiguity-averse (Garlappi et al., 2007). Therefore, we assume investors are ambiguityaverse and adopt the multiple-prior model in our study.

\section{DATA}

To measure the impact of ambiguity on market returns, we collected the daily closing price, bid price, ask price and turnover by volume of the equity traded fund of FTSE100 from Datastream. ETF FTSE100 is traded in pound sterling on the London Stock Exchange, which is a good proxy for the market return of the UK stock market.

The sample period starts from 22 June, 2009 and ends on 1August, 2017. As such, we collected a total of 2.049 observations, which composed a relatively large sample.

\section{METHODOLOGY}

The daily closing prices were used to obtain the daily log returns of ETF FTSE100, which were calculated as:

$$
r_{t}=\ln \frac{P_{t}}{P_{t-1}}
$$

where $r_{t}$ is the daily log return of ETF FTSE100 at time $\mathrm{t}$ and $P_{t}$ is the price of ETF FTSE100 at time $t$.

\subsection{Ambiguity measure}

We then used bid and ask price to get the bid-ask spread, which estimates the degree of ambiguity. The ambiguity measure was constructed with inspiration from the ambiguity theory, especially the multiplepriors preference model (Gilboa \& Schmeidler, 1989). Assume that the investors have a homogeneous reference model on the distribution of the stock market return and hence a homogeneous reference return, $r^{*}$, the buyers and sellers of the market portfolio have different "worst-case scenarios" and hence use different priors of the stock market return because of ambiguity. Buyers are worried about a price decrease since they take a long position and will incur a loss if the price goes down. As such, their worst case is that the price goes below the reference price when they enter the long position, which makes them require a compensation for that uncertainty due to lack of information. Hence, they will quote a bid price as low as possible to get compensation for ambiguity. In terms of return, they will require the reference return minus an ambiguity term to compensate the possible loss they might face when they enter the long position. Suppose the degree of ambiguity expressed by return is $k$, then the prior return of the buyers will be $r^{*}-k$. Similarly, sellers fear price increase because they are in a short position and will incur a loss if the price goes up. Therefore, their worst case is that the price goes beyond the reference price when they enter the short position. Hence, they will quote an ask price as high as possible to compensate ambiguity due to lack of information.

In terms of return, they will require the reference return plus an ambiguity term, $r^{*}+k$, to get the compensation for bearing ambiguity. In summary, we have:

$$
\begin{aligned}
& \ln \frac{B}{P_{t-1}}=\ln B-\ln P_{t-1}=r^{*}-k \\
& \ln \frac{A}{P_{t-1}}=\ln A-\ln P_{t-1}=r^{*}+k,
\end{aligned}
$$

where $B$ and $A$ are bid and ask price, respectively, $P_{t-1}$ is the stock market price at time $t-1$.

If we subtract equation (6) from equation (7), we will get:

$$
\ln A-\ln B=2 k .
$$

Equation (8) provides us with a method of measuring degree of ambiguity $k$ and hence we use the following equation as a proxy of degree of ambiguity.

$$
K=\frac{\ln A-\ln B}{2} .
$$

\subsection{The role of market makers}

Having calculated the bid-ask spread using equation (9), we take the role of market makers into account because market makers make profits through the bid-ask spread. Grossman and Miller (1988) developed a market making model, taking transaction costs into consideration, which we adopted as the theoretical base in terms of the role of 
market makers in our study. Suppose there are two liquidity traders in the market, L1 and L2. L1 sells $m$ units of stocks at time 1 and L2 buys $m$ units at time 2 . If we denote the number of market makers as $n$ and the stock price at time $i$ is $S_{i}$, then the present value of the stock at time 0 will be:

$$
S_{0}=\mu-A \sigma^{2} \cdot \frac{m}{n+1}-2 c \cdot \frac{n}{n+1},
$$

where the stock price is assumed to be normally distributed with mean $\mu$ and variance $\sigma^{2}, c$ is the transaction costs per unit of the stock; and $A$ is the degree of risk aversion of the traders, namely both the liquidity traders and the market makers.

Equation (10) provides us with an insight of the mechanism of market making. Liquidity with the presence of transaction costs can therefore be calculated as:

$$
L=\frac{m}{n+1}+2 \frac{c \cdot n}{A \sigma^{2} \cdot(n+1)}
$$

Equation (11) tells us that liquidity, or the role of the market makers in the financial markets can be affected by trading volume $\mathrm{m}$, number of market makers n, degree of risk aversion $A$, transaction costs $\mathrm{c}$ and volatility of the stock price $\sigma^{2}$.

The number of the market makers in the financial markets and the degree of risk aversion are difficult to measure empirically. On the other hand, volatility interacts with ambiguity in asset pricing processes, as is illustrated by Epstin and Schneider (2010). This makes us reluctant to remove the impact of volatility on the stock prices, or the spread. As a result, we used turnover by volume to measure the impact of market makers on the spread.

As such, we regressed the spread calculated using the right-hand side of equation (9) on turnover by volume to remove the part of variation in the bid- ask spread caused by the impact of market makers and then we treated the residuals as a measure of the degree of ambiguity.

\subsection{Vector Autoregression (VAR) model}

To investigate the interactions between the UK stock market return and ambiguity, we applied the VAR model. Since so far there is little empirical work showing the relationship between the UK stock market return and ambiguity, a good way of uncovering the interactions between them is to analyse them as a system. Therefore, we applied the VAR model, which can be expressed as:

$$
y_{t}=\beta_{0}+\beta_{1} \cdot y_{t-1}+\ldots+\beta_{p} \cdot y_{t-p}+\varepsilon_{t},
$$

where $y_{t}$ is a vector of dependent variables and the number of dependent variables determines the number of equations; $\beta$ are a vector of coefficients of different equations; $p$ is the order of the lags included in the model, which is determined by information criteria; $\varepsilon_{t}$ is a vector of error terms.

In our case, we have two dependent variables, the daily $\log$ returns $r_{t}$ and the ambiguity measure $k$ and hence we have two equations in the VAR analysis, which are the return equation:

$$
\begin{aligned}
& r_{t}=r_{t-1}+r_{t-2}+\ldots+r_{t-p}+ \\
& +k_{t-1}+k_{t-2}+\ldots+k_{t-q}+\varepsilon_{t}
\end{aligned}
$$

and the ambiguity measure equation:

$$
\begin{aligned}
& k_{t}=r_{t-1}+r_{t-2}+\ldots+r_{t-p}+ \\
& +k_{t-1}+k_{t-2}+\ldots+k_{t-q}+\varepsilon_{t},
\end{aligned}
$$

\begin{tabular}{|c|c|c|c|c|}
\hline Variables & Mean & Std. Dev. & Skewness & Kurtosis \\
\hline Volume & 12.24363 & 10.64744 & 2.439972 & 13.52941 \\
\hline Spread & 0.0029146 & 0.0074142 & 11.83696 & 163.7834 \\
\hline Return & 0.0006019 & 0.0196546 & -0.2925296 & 5.121268 \\
\hline
\end{tabular}

where $p$ and $q$ are the number of lags included in the VAR model, which we selected based on information criteria.

Table 3. Summary statistics

Notes: Volume denotes turnover by volume; spread represents $k$, which is calculated by equation (9); and return is the daily $\log$ return of ETF FTSE100. 

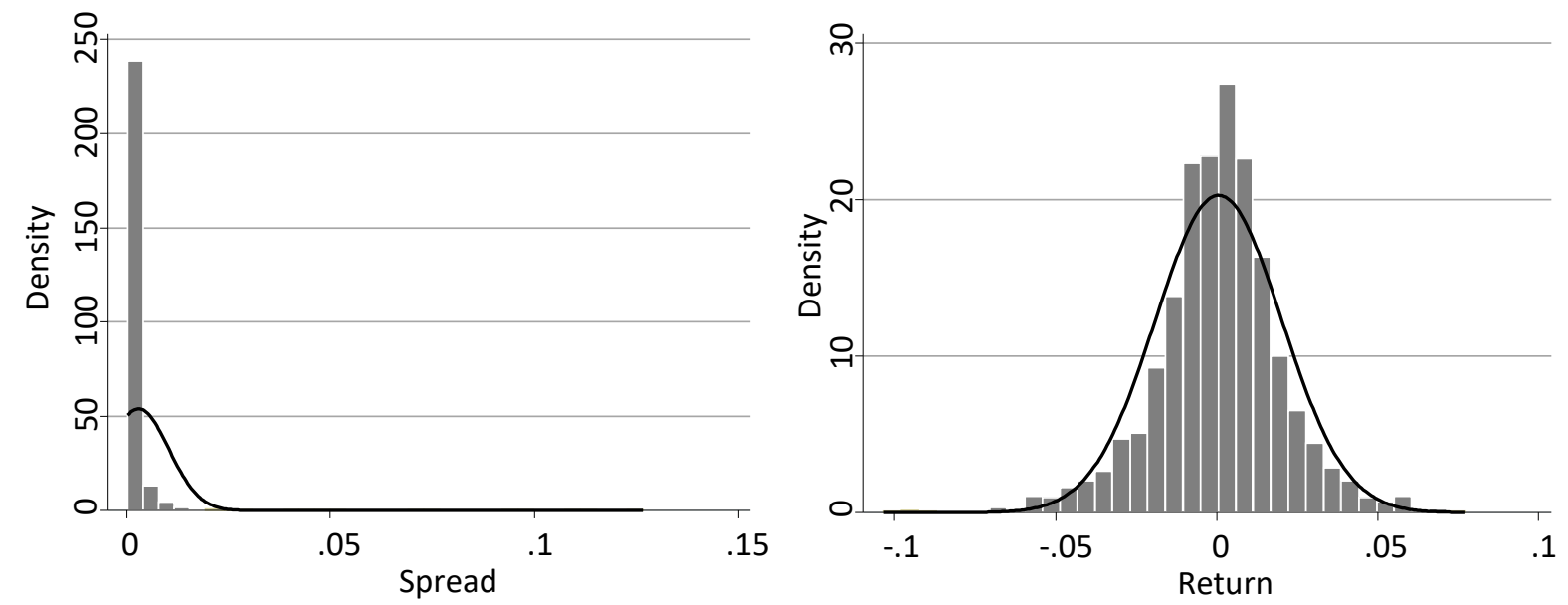

Notes: Spread represents $k$, which is calculated by equation (9); and return is the daily log return of ETF FTSE100.

Figure 1. Histogram of spread and return

\subsection{Preliminary analysis}

The summary statistics of the variables is presented in Table 3. We can see from the table that spread is positively skewed and the leptokurtic, while the distribution of return seems close to a normal distribution, which has a skewness of zero and a kurtosis of 3. The histogram displayed in Figure 1 provides further evidence. Since spread and return are used as dependent variables, we need to make sure they are approximately normal. As such, we took natural logarithm of spread to transform it to an approximately normally distributed variable.

The transformed spread now has a skewness of 1.29077 and a kurtosis of 7.549364 with mean -
6.276782 and standard deviation 0.7277081 and the histogram is shown is Figure 2, where we can see that the variable is now approximately normally distributed.

We then used the natural logarithm of spread to do the analysis. The time series plots of the variables are presented in Figure 3. The plots suggest that the series seem stationary.

\subsubsection{Preliminary analysis of ambiguity measure}

As is mentioned before, bid-ask spread is found to be related to the impact of market makers. To remove this effect, we regressed the natural logarithm of spread on turnover by volume (volume) and the residuals were the ambiguity measure

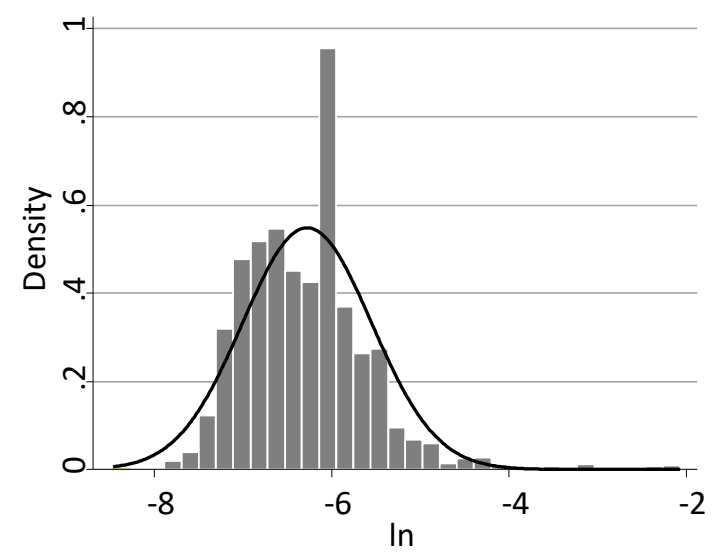

Notes: spread represents $k$, which is calculated by equation (9); and $l n$ is the natural logarithm of $k$.

Figure 2. Histogram of natural logarithm of spread 

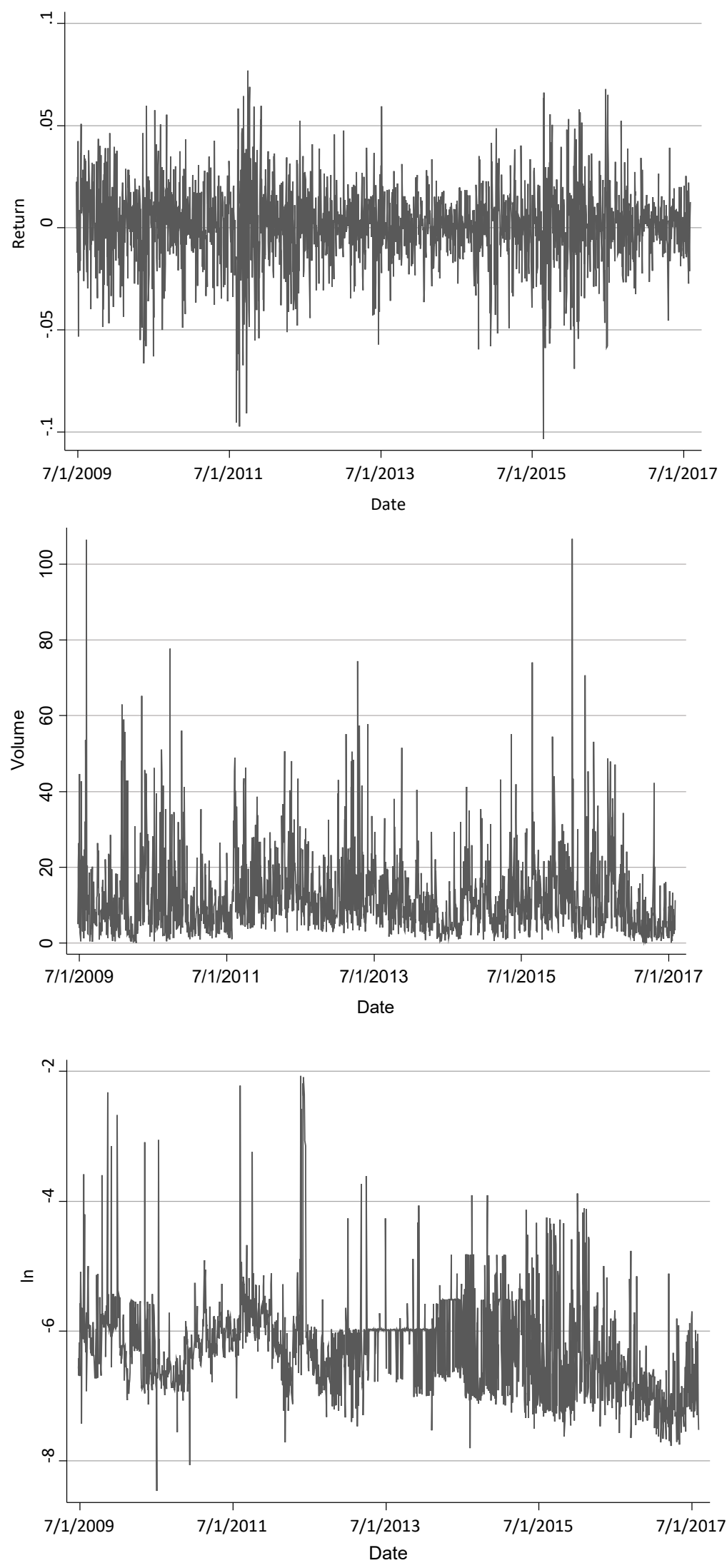

Notes: return is the daily log return of ETF FTSE100; volume denotes turnover by volume; $l n$ is the natural logarithm of $k$.

Figure 3. Time series plots of volume, natural logarithm of spread and return 
Table 4. Regression result with Newey-West standard errors

\begin{tabular}{|c|c|c|c|c|}
\hline$L n$ spread & Coefficient & $\begin{array}{l}\text { New-West } \\
\text { Std. Error }\end{array}$ & $\mathbf{t}$ & p-value \\
\hline Volume & 0.0038211 & 0.0027132 & 1.41 & 0.159 \\
\hline Constant & $-6.323566^{* * *}$ & 0.0597324 & -105.86 & 0.000 \\
\hline
\end{tabular}

Notes: $L n$ spread denotes the natural logarithm of $k$, and volume denotes turnover by volume.

orthogonalized of the impact of market makers. Thus, we ran an ordinary least squares (OLS) regression using the following model.

$$
\ln k_{t}=\beta_{0}+\beta_{1} \cdot \text { Volume }_{t}+\varepsilon_{t},
$$

where $k$ is the ambiguity measure, which is calculated by equation (9) and volume is turnover by volume. To ensure the validity of the regression result, we checked for heteroscedasticity and autocorrelation after the regression.

The Breusch-Pagan test showed a $p$-value of 0.0000 , indicating the presence of heteroscedasticity at $1 \%$ significance level. On the other hand, the BreuschGrodfrey LM test generated a $p$-value of 0.0000 for 20 lags, meaning that there is autocorrelation. Therefore, we applied Newey-West standard errors to run the regression. The regression result is shown in Table 4.

The regression result indicates that volume is not statistically significant at $10 \%$ significance level, meaning that the relationship between trading volume and the natural logarithm of the ambiguity in equation (15) is not statistically significant. This is reasonable since ETF FTSE100 is a relatively liquid equity traded fund and the UK stock mar- ket is an established stock market. As such, market makers may not contribute to the variation of the bid-ask spread significantly. We then used the ambiguity measure calculated by equation (9) to run the VAR model.

\subsubsection{VAR model specification}

VAR model requires stationary dependent variables and hence we began the formal analysis with the Augmented Dickey-Fuller test for unit root. The test results are shown in Table 5.

The null hypothesis of the augmented DickeyFuller test is non-stationarity and hence, a small $p$-value indicates stationarity of the series upon rejection of the null. Thus, the test results show that both the natural logarithm of the ambiguity measure and return of ETF FTSE100 seem stationary at $1 \%$ significance level. Therefore, the two variables are ready for the VAR model without modification.

On the other hand, it is important to decide the lag number, or the lag order $\mathrm{p}$ of the model to implement the VAR analysis. We selected lag order by information criteria and the result is displayed in Table 6.

Table 5. Augmented Dickey-Fuller test result

\begin{tabular}{c|c|c}
\hline Variable & Z & p-value \\
\hline$L n$ ambiguity & -4.397 & 0.0003 \\
Return & -9.546 & 0.0000 \\
\hline
\end{tabular}

Notes: $L n$ ambiguity denotes the natural logarithm of $k$, and return denotes the daily log return of ETF FTSE100.

Table 6. Information criteria for lag selection

\begin{tabular}{c|c|c|c|c}
\hline & FPE & AIC & HQIC & SBIC \\
\hline Lag & 13 & 13 & 5 & 5 \\
\hline
\end{tabular}

Notes: FPE is the final prediction error measure; AIC is the Akaike's information criterion; HQIC is the Hannan and Quinn information criterion; and SBIC is the Schwarz's Bayesian information criterion. 
The result in Table 6 shows that FPE and AIC criterion yield different results from HQIC and SBIC criterion. Lütkepohl (2006) suggested using FPE and AIC for small sample. HQIC and SBIC seem to work better with large samples. However, if we choose a smaller number of lags, we are running the risk of neglecting effects of other lags. As such, we mainly used the VAR results with both 5 lags while treated the VAR results with 13 lags as a robustness check. Therefore, the return equation of our VAR model is:

$r_{t}=r_{t-1}+r_{t-2}+\ldots+r_{t-5}+$

$+\ln k_{t-1}+\ln k_{t-2}+\ldots+\ln k_{t-5}+\varepsilon_{t}$.

and $L n$ ambiguity equation is:

$$
\begin{aligned}
& \ln k_{t}=r_{t-1}+r_{t-2}+\ldots+r_{t-5}+ \\
& +\ln k_{t-1}+\ln k_{t-2}+\ldots+\ln k_{t-5}+\varepsilon_{t},
\end{aligned}
$$

where $\ln k_{t}$ is the natural logarithm of the ambiguity measure $k$ at time $t$, and $r_{t}$ is the daily log return of ETF FTSE100 at time $t$.

The return equation of the robustness test is:

$$
\begin{aligned}
& r_{t}=r_{t-1}+r_{t-2}+\ldots+r_{t-13}+ \\
& +\ln k_{t-1}+\ln k_{t-2}+\ldots+\ln k_{t-13}+\varepsilon_{t},
\end{aligned}
$$

and the $L n$ Ambiguity equation is:

$$
\begin{aligned}
& \ln k_{t}=r_{t-1}+r_{t-2}+\ldots+r_{t-13}+ \\
& +\ln k_{t-1}+\ln k_{t-2}+\ldots+\ln k_{t-13}+\varepsilon_{t},
\end{aligned}
$$

where $\ln k_{t}$ is the natural logarithm of the ambiguity measure $k$ at time $t$, and $r_{t}$ is the daily $\log$ return of ETF FTSE100 at time $t$.

\section{EMPIRICAL RESULT}

Table 7 presents the empirical result of the VAR model with 5 lags. From panel A, we can see that the fourth lag of the daily return of ETF FTSE100 is statistically significant at $1 \%$ level and the second lag of the ambiguity measure is statistically significant at $10 \%$ level in the return equation. The statistically significant coefficient of the second lag of the daily return suggests that a $1 \%$ increase in the daily return that happened four days ago would decrease the daily return today by around $5.79 \%$ at $1 \%$ significance level. On the other hand, the coefficient of the fourth lag of the ambiguity measure suggests that an increase in the degree of ambiguity would increase the stock market return at $10 \%$ significance level. This also implies that when the degree of ambiguity increases, investors would require an ambiguity premium, which in turn increases the return. However, the Granger causality test indicates that $L n$ ambiguity does not Granger-cause the variation in stock market return at $10 \%$ significance level. This can be further implied from the orthogonalised impulse response function in Figure 4, which shows that the response of the daily return of ETF FTSE100 to a $1 \%$ change in the ambiguity measure is not statistically significant at $5 \%$ level.

The rejection of the causality relationship between the daily return and the ambiguity measure implies that past values of the ambiguity measure cannot be used to predict the daily returns of the stock market. This suggests that ambiguity measure cannot be used to predict the stock market return linearly. However, this does not mean that the degree of ambiguity cannot predict the volatility of stock returns. For instance, Epstein and Schneider (2010) showed that ambiguity aversion affects the premium of stocks generates excess variation of stock returns. Therefore, even though the degree of ambiguity does not Granger-cause the daily return of the stock market, it seems to affect its premium, which is in line with our empirical results.

Panel B illustrates the regression result of the $L n$ ambiguity equation. The third lag of stock market return is statistically significant at 5\% level and all the lags of $L n$ ambiguity are $1 \%$ significant. This result indicates that an increase in the daily return of the stock market tends to increase the degree of ambiguity of the investors, which in turn implies that investors tend to be confused, or ambiguous about the returns from the previous three days.

On the other hand, past degree of ambiguity tends to persist and the degree of ambiguity can be accumulated at least for a period of five days. The Granger causality test suggests that return does not cause the variation in $L n$ ambiguity at $10 \%$ significance level. This is also consistently visualized from Figure 4, where we can see that the response of the ambiguity measure to a $1 \%$ change in the daily return of ETF FTSE100 is not statistically significant at $5 \%$ level. However, it is notice- 
Table 7. VAR result with 5 lags

\begin{tabular}{|c|c|c|c|}
\hline \multicolumn{4}{|c|}{ Panel A. Return equation } \\
\hline & Lag & Coefficient & p-value \\
\hline \multirow{5}{*}{ Return } & 1 & 0.0130999 & 0.554 \\
\hline & 2 & -0.0198759 & 0.368 \\
\hline & 3 & 0.0004016 & 0.986 \\
\hline & 4 & $-0.0579445^{* * *}$ & 0.009 \\
\hline & 5 & -0.0321777 & 0.146 \\
\hline \multirow{5}{*}{$L n$ ambiguity } & 1 & 0.0003357 & 0.622 \\
\hline & 2 & $0.0013214 *$ & 0.056 \\
\hline & 3 & -0.0001828 & 0.794 \\
\hline & 4 & -0.0008111 & 0.240 \\
\hline & 5 & -0.000331 & 0.627 \\
\hline Constant & & 0.0027442 & 0.612 \\
\hline Granger causality & $L n$ ambiguity & 5.079 & 0.406 \\
\hline Test statistics & All & 5.079 & 0.406 \\
\hline \multicolumn{4}{|c|}{ Panel B. $L n$ ambiguity equation } \\
\hline \multirow{5}{*}{ Return } & 1 & -0.5262383 & 0.461 \\
\hline & 2 & -0.757903 & 0.288 \\
\hline & 3 & $1.4705^{* *}$ & 0.039 \\
\hline & 4 & -1.131771 & 0.113 \\
\hline & 5 & 0.598707 & 0.402 \\
\hline \multirow{5}{*}{$L n$ ambiguity } & 1 & $0.2005302^{* * *}$ & 0.000 \\
\hline & 2 & $0.1832782 * * *$ & 0.000 \\
\hline & 3 & $0.0854842 * * *$ & 0.000 \\
\hline & 4 & $0.1087189^{* * *}$ & 0.000 \\
\hline & 5 & $0.1251023^{* * *}$ & 0.000 \\
\hline Constant & & $-1.863846^{* * *}$ & 0.000 \\
\hline Granger causality & Return & 8.9776 & 0.110 \\
\hline Test statistics & All & 8.9776 & 0.110 \\
\hline
\end{tabular}

Notes: $L n$ ambiguity denotes the natural logarithm of $k$; and return denotes the daily log return of ETF FTSE100.** denotes $1 \%$ significance level; ${ }^{* *}$ denotes $5 \%$ significance level; and ${ }^{*}$ denotes $1 \%$ significance level.
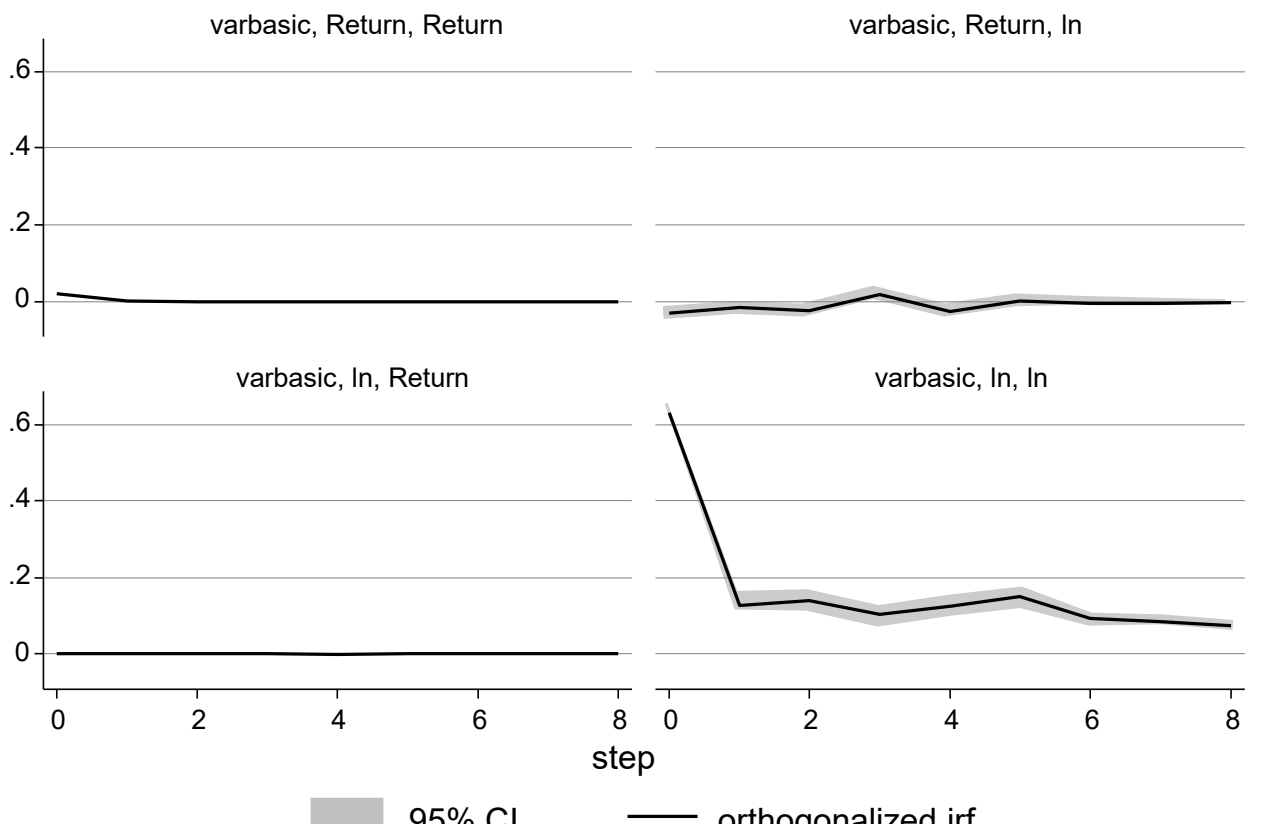

varbasic, In, In

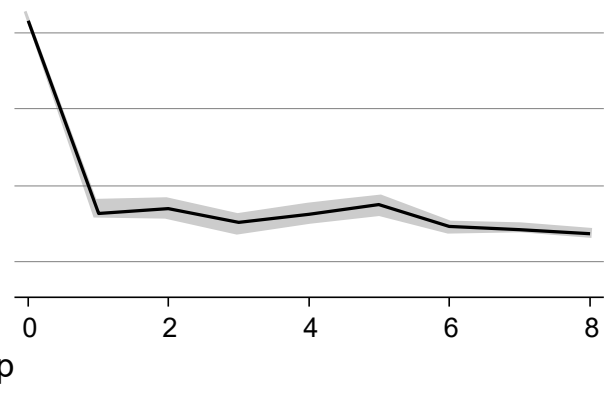

$95 \% \mathrm{Cl}$ orthogonalized irf

Note: Graphs by irfname, impulse variable, and response variable.

Figure 4. Orthogonalized impulse-response function (VAR with 5 lags) 
Table 8. VAR result with 13 lags

\begin{tabular}{|c|c|c|c|}
\hline \multicolumn{4}{|c|}{ Panel A. Return equation } \\
\hline & Lag & Coefficient & p-value \\
\hline \multirow{13}{*}{ Return } & 1 & 0.018454 & 0.405 \\
\hline & 2 & -0.0250737 & 0.258 \\
\hline & 3 & -0.0000186 & 0.999 \\
\hline & 4 & $-0.0619793^{* * *}$ & 0.005 \\
\hline & 5 & -0.0345302 & 0.120 \\
\hline & 6 & 0.0131282 & 0.554 \\
\hline & 7 & -0.0217691 & 0.327 \\
\hline & 8 & -0.0342149 & 0.123 \\
\hline & 9 & -0.0116832 & 0.599 \\
\hline & 10 & 0.0037045 & 0.867 \\
\hline & 11 & 0.0039689 & 0.858 \\
\hline & 12 & -0.0337713 & 0.128 \\
\hline & 13 & -0.0005051 & 0.982 \\
\hline \multirow{13}{*}{$L n$ ambiguity } & 1 & 0.0001079 & 0.877 \\
\hline & 2 & $0.0014429 * *$ & 0.041 \\
\hline & 3 & -0.0002669 & 0.708 \\
\hline & 4 & -0.0009175 & 0.197 \\
\hline & 5 & -0.0004071 & 0.568 \\
\hline & 6 & 0.0000153 & 0.983 \\
\hline & 7 & 0.0000513 & 0.943 \\
\hline & 8 & -0.0007193 & 0.314 \\
\hline & 9 & 0.0009008 & 0.206 \\
\hline & 10 & -0.0000149 & 0.983 \\
\hline & 11 & 0.0000924 & 0.896 \\
\hline & 12 & 0.0006202 & 0.376 \\
\hline & 13 & -0.0002672 & 0.699 \\
\hline Constant & & 0.0047421 & 0.443 \\
\hline Granger causality & $L n$ ambiguity & 9.2101 & 0.757 \\
\hline Test statistics & All & 9.2101 & 0.757 \\
\hline \multicolumn{4}{|c|}{ Panel B. $L n$ ambiguity Equation } \\
\hline \multirow{13}{*}{ Return } & 1 & -0.7627861 & 0.280 \\
\hline & 2 & -0.8046075 & 0.254 \\
\hline & 3 & $1.24295^{*}$ & 0.078 \\
\hline & 4 & $-1.394665^{* *}$ & 0.048 \\
\hline & 5 & 0.3005252 & 0.671 \\
\hline & 6 & 0.5933196 & 0.401 \\
\hline & 7 & -0.493998 & 0.484 \\
\hline & 8 & $-1.376015^{*}$ & 0.051 \\
\hline & 9 & $-1.289266^{*}$ & 0.068 \\
\hline & 10 & 0.5125471 & 0.468 \\
\hline & 11 & $-2.454877^{* * *}$ & 0.001 \\
\hline & 12 & -0.6148589 & 0.384 \\
\hline & 13 & $-1.198089 *$ & 0.090 \\
\hline \multirow{13}{*}{$L n$ ambiguity } & 1 & $0.1691672 * * *$ & 0.000 \\
\hline & 2 & $0.1541337^{* * *}$ & 0.000 \\
\hline & 3 & $0.0586237 * * *$ & 0.010 \\
\hline & 4 & $0.075024 * * *$ & 0.001 \\
\hline & 5 & $0.0856396 * * *$ & 0.000 \\
\hline & 6 & $0.0399135^{*}$ & 0.080 \\
\hline & 7 & 0.0281818 & 0.216 \\
\hline & 8 & 0.0234796 & 0.302 \\
\hline & 9 & -0.003994 & 0.860 \\
\hline & 10 & 0.0353478 & 0.118 \\
\hline & 11 & $0.0475343^{* *}$ & 0.035 \\
\hline & 12 & 0.0334648 & 0.133 \\
\hline & 13 & $0.0609314^{* * *}$ & 0.006 \\
\hline Constant & & $-1.205821 * * *$ & 0.000 \\
\hline Granger causality & Return & $32.769 * * *$ & 0.002 \\
\hline Test statistics & All & $32.769 * * *$ & 0.002 \\
\hline
\end{tabular}

Notes: $L n$ ambiguity denotes the natural logarithm of $k$, and return denotes the daily log return of ETF FTSE100. ${ }^{* *}$ denotes $1 \%$ significance level; ${ }^{* *}$ denotes $5 \%$ significance level; and ${ }^{\star}$ denotes $1 \%$ significance level. 


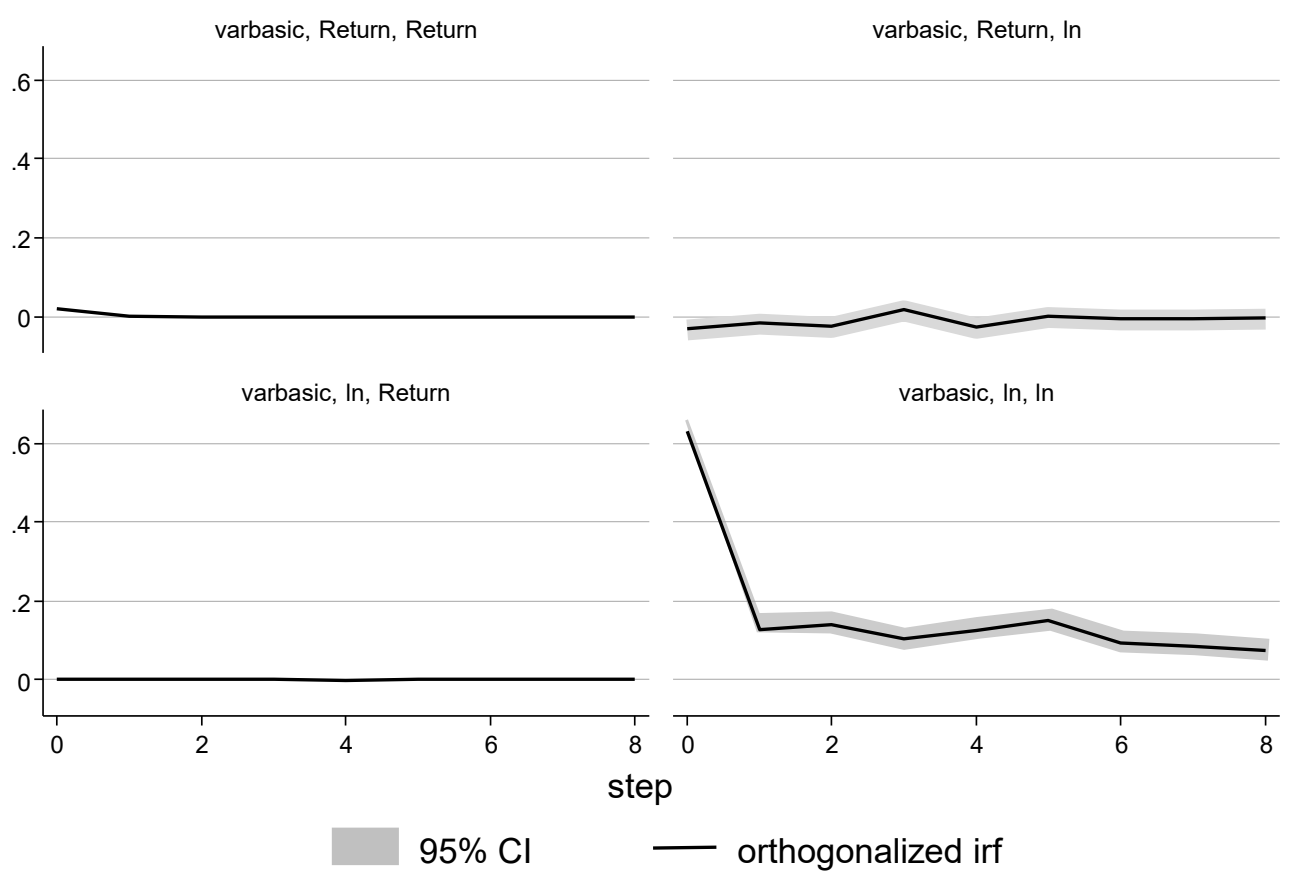

Note: Graphs by irfname, impulse variable, and response variable.

Figure 5. Orthogonalized impulse-response function (VAR with 13 lags)

able that in Panel B, the $p$-value of the Granger causality test is 0.110 , which is close to the $10 \%$ significance level. This implies that past daily returns of the stock market might predict the degree of ambiguity to a very weak degree.

Overall, the VAR result with 5 lags seems to suggest that the effect of ambiguity on stock market return exists but there is no/weak Granger causality relationship between the daily return of the ETF FTSE100 and the ambiguity measure.

\section{ROBUSTNESS TEST}

The VAR results with 13 lags in Table 8 represent robustness checks to our empirical results. In the return equation, the second lag is again statistically significant but at 5\% level instead of $10 \%$ level this time, as is shown in panel $\mathrm{A}$. The result of Granger causality test still suggests that $L n$ ambiguity does not Granger cause stock market return, which is consistently shown in the orthogonalized impulse-response function in Figure 5.

In the $L n$ ambiguity equation, the third, eighth, ninth and thirteenth lags are statistically sig- nificant at $10 \%$ level, as is shown in Panel B. The fourth lag is statistically significant at $5 \%$ level and the eleventh lag is statistically significant at $1 \%$ level. The Granger causality test indicates that the stock market return causes $L n$ ambiguity at $1 \%$ significance level.

We notice that the degree of ambiguity influences the daily return of the UK stock market when wecompare the results of VAR with 5 lags and VAR with 13 lags. Moreover, the result of the VAR model with 13 lags suggests that changes in stock market return can Granger-cause variation in the ambiguity measure. Such Granger causality is statistically weak in the 5 lags case. When return decreases and hence price goes down, the degree of ambiguity will increase, and when price goes up, the degree of ambiguity tends to decrease. This seems to resemble the prospect theory in behavioural finance, which says that investors are lossadverse, except that here we assume investors are ambiguity-averse.

In addition, the VAR result with 13 lags consistently indicates that past values of the ambiguity measure seem to persist and the degree of ambiguity can be accumulated for a period of five days at $1 \%$ significance level. 


\section{CONCLUSION}

Overall, the two sets of results show that the degree of ambiguity from the previous two days might affect stock market returns. An increase in the degree of ambiguity two days ago is associated with a positive premium required by the investors. On the other hand, the degree of ambiguity tends to be affected by its past five-day values. Thus, the degree of ambiguity seems to persist for five days until investors update their prior. This result is robust when 13 lags are added to the VAR model. The intuition behind the result is that the degree of ambiguity can affect the returns of the UK stock market and UK stock market returns can in turn have an impact on the degree of ambiguity. We observe that the degree of ambiguity does not seem to predict stock market returns in the UK when we apply linear models. However, this does not mean that there is no non-linear relationship between the degree of ambiguity and stock market returns or stock returns. Viale et al. (2014) discovered a non-linear relationship between stock returns and the ambiguity measure. Therefore, further studies can investigate the interactions between the ambiguity measure that we developed in our study and stock returns using non-linear models.

\section{REFERENCES}

1. Anderson, E. W., Hansen, L. P., \& Sargent, T. J. (2003). A quartet of semigroups formodel specification, robustness, prices of risk, and model detection. Journal of The European Economic Association, 1(1), 68-123.

2. Barillas, F., Hansen, L. P., \& Sargent, T. J. (2009). Doubts or variability? Journal of Economic Theory, 144(6), 2388-2418. https://doi.org/10.1016/j. jet.2008.11.014

3. Bernoulli, D. (1738). Specimen theoriae novae de mensura sortis. Commentarii Academiae Scientiarum Imperialis Petropolitanae, 5, 175-192.

4. Boyarchenko, N. (2012). Ambiguity shifts and the 2007-2008 financial crisis. Journal of Monetary Economics, 59(5), 493-507. https://doi.org/10.1016/j.jmoneco.2012.04.002

5. Chen, Z., \& Epstein, L. (2002). Ambiguity, risk, and asset returns in continuous time. Econometrica, 70(4), 1403-1443.

6. Chen, H., Ju, N., \& Miao, J. (2014). Dynamic asset allocation with ambiguous return predictability. Review of Economic Dynamics, 17(4), 799-823. https://doi.org/10.1016/j. red.2013.12.001

7. Conte, A., \& Hey, J. D. (2013). Assessing multiple prior models of behaviour under ambiguity. Journal of Risk and Uncertainty, 46(2), 113-132.
8. Cochrane, J. H. (2009). Asset Pricing (Revised Edition). Princeton University press.

9. Dimmock, S. G., Kouwenberg, R., Mitchell, O. S., \& Peijnenburg, K. (2016). Ambiguity aversion and household portfolio choice puzzles: Empirical evidence. Journal of Financial Economics, 119(3), 559-577. https://doi. org/10.1016/j.jfineco.2016.01.003

10. Dow, J., \& Werlang, S. R. da Costa (1992). Uncertainty aversion, risk aversion, and the optimal choice of portfolio. Econometrica, 60(1), 197-204.

11. Duffie, D., \& Epstein, L. G. (1992). Stochastic differential utility. Econometrica, 60(2), 353-394.

12. Ellsberg, D. (1961). Risk, ambiguity, and the Savage axioms. The Quarterly Journal of Economics, 75(4), 643-669.

13. Epstein, L. G., \& Wang, T. (1994). Intertemporal asset pricing under Knightian uncertainty. Econometrica, 62(2), 283-322.

14. Epstein, L. G., \& Schneider, M. (2008). Ambiguity, information quality, and asset pricing. The Journal of Finance, 63(1), 197-228.

15. Epstein, L. G., \& Schneider, M. (2010). Ambiguity and asset markets. Annual Review of Financial Economics, 2, 315-346.
16. Etner, J., Jeleva, M., \& Tallon, J. M. (2012). Decision theory under ambiguity. Journal of Economic Surveys, 26(2), 234-270. Retrieved from https://hal.archives-ouvertes. fr/halshs-00429573v1/document

17. Garlappi, L., Uppal, R., \& Wang, T. (2007). Portfolio selection with parameter and model uncertainty: A multi-prior approach. Review of Financial Studies, 20(1), 41-81.

18. Gilboa, I., \& Schmeidler, D. (1989). Maxmin expected utility with non-unique prior. Journal of mathematical economics, 18(2), 141-153.

19. Grossman, S. J., \& Miller, M. H. (1988). Liquidity and market structure. The Journal of Finance, 43(3), 617-637.

20. Guidolin, M., \& Rinaldi, F. (2013). Ambiguity in asset pricing and portfolio choice: A review of the literature. Theory and Decision, 74(2), 183-217.

21. Hansen, L. P., \& Sargent, T. J. (2001). Robust control and model uncertainty. The American Economic Review, 91(2), 60-66.

22. Illeditsch, P. K. (2009). Ambiguous Information, Risk Aversion, and Asset Pricing (No 802, 2009 Meeting Papers from Society for Economic Dynamics).

23. Jeong, D., Kim, H., \& Park, J. Y. (2015). Does ambiguity matter? Estimating asset pricing models with a multiple-priors recursive 
utility. Journal of Financial Economics, 115(2), 361-382. https://doi.org/10.1016/j.jfineco.2014.10.003

24. Ju, N., \& Miao, J. (2012). Ambiguity, learning, and asset returns. Econometrica, 80(2), 559-591.

25. Klibanoff, P., Marinacci, M., \& Mukerji, S. (2005). A smooth model of decision making under ambiguity. Econometrica, 73(6), 1849-1892. https:// doi.org/10.1111/j.14680262.2005.00640.x

26. Klibanoff, P., Marinacci, M., \& Mukerji, S. (2009). Recursive smooth ambiguity preferences. Journal of Economic Theory, 144(3), 930-976.

27. Knight, F. H. (1921). Risk, uncertainty and profit. New York: Hart, Schaffner and Marx.

28. Liu, H. (2011). Dynamic portfolio choice under ambiguity and regime switching mean returns. Journal of Economic Dynamics and Control, 35(4), 623-640.

29. Lütkepohl, H. (2006) Forecasting with VARMA Models. Handbook of Economic Forecasting, 1, 287-325.

30. Maccheroni, F., Marinacci, M., \& Rustichini, A. (2006). Ambiguity aversion, robustness, and the variational representation of preferences. Econometrica, 74(6), 1447-1498.

31. Miao, J. (2009). Ambiguity, risk and portfolio choice under incomplete information. Annals of Economics and Finance, 10(2), 257-279.

32. Ozsoylev, H., \& Werner, J. (2011). Liquidity and asset prices in rational expectations equilibrium with ambiguous information. Economic Theory, 48(2), 469-491.

33. Routledge, B. R., \& Zin, S. E. (2009). Model uncertainty and liquidity. Review of Economic dynamics, 12(4), 543-566.

34. Strzalecki, T. (2011). Axiomatic foundations of multiplier preferences. Econometrica, 79(1), 47-73. http://dx.doi.org/10.3982/ ECTA8155

35. Teräsvirta, T. (1994). Specification, estimation, and evaluation of smooth transition autoregressive models. Journal of the American Statistical association, 89(425), 208-218.

36. Viale, A. M., Garcia-Feijoo, L., \& Giannetti, A. (2014). Safety First, Learning Under Ambiguity, and the Cross-Section of Stock Returns. The Review of Asset Pricing Studies, 4(1), 118-159. https://doi.org/10.1093/rapstu/ rat017

37. Von Neumann, J., \& Morgenstern, O. (1944). Games and economic behavior. Princeton, NJ. 